\title{
Supporting Information on: Reaction Kinetics of the Formation of Poly(oxymethylene) Dimethyl Ethers from Formaldehyde and Methanol in Aqueous
}

\section{Solutions}

\author{
Niklas Schmitz, Jakob Burger, ${ }^{*}$ and Hans Hasse \\ Laboratory of Engineering Thermodynamics, University of Kaiserslautern, Germany \\ E-mail: jakob.burger@mv.uni-kl.de
}

\section{Experimental Results}

Numerical results of the experimentally obtained concentration profiles (overall mass fractions over time) are given in Table S1 to Table S11. Caused by taking samples of the liquid phase for the analysis, the totals mass of the liquid phase $m_{\mathrm{L}}$ is a step function of the time, it is given for every experiment. The temperature, the mass of dry catalyst, and the catalyst capacity are also given for every experiment.

${ }^{*}$ To whom correspondence should be addressed 


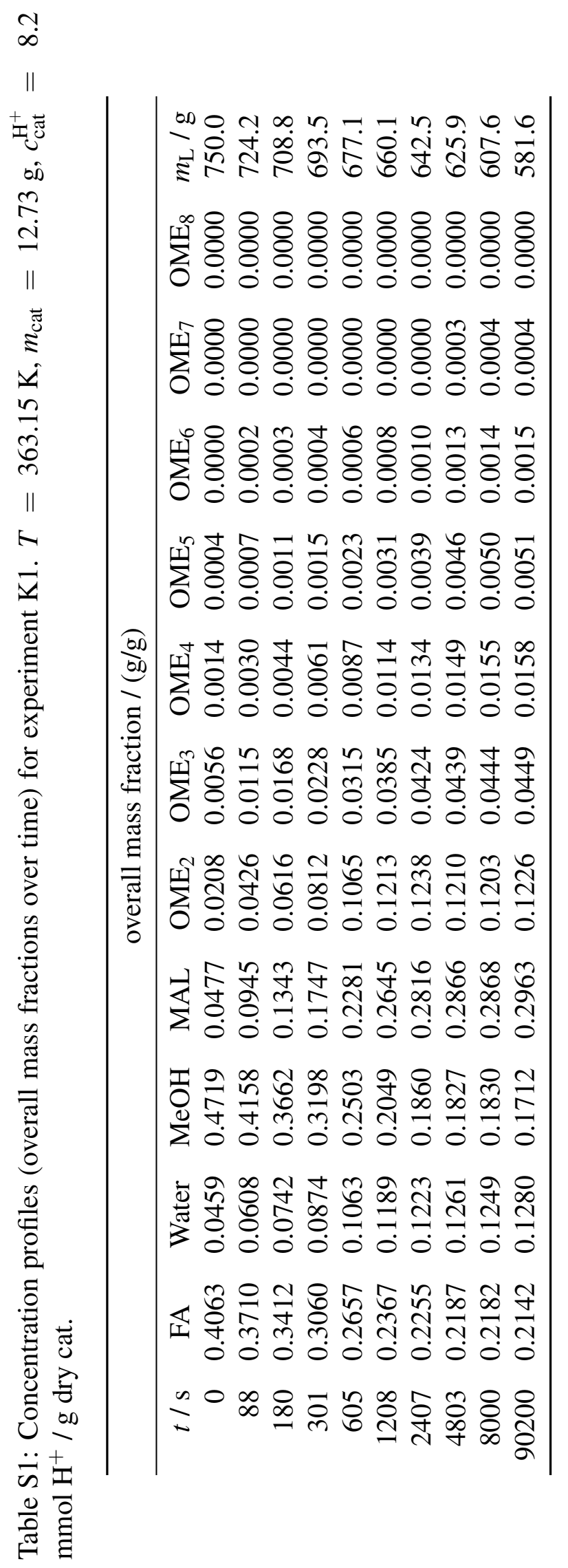




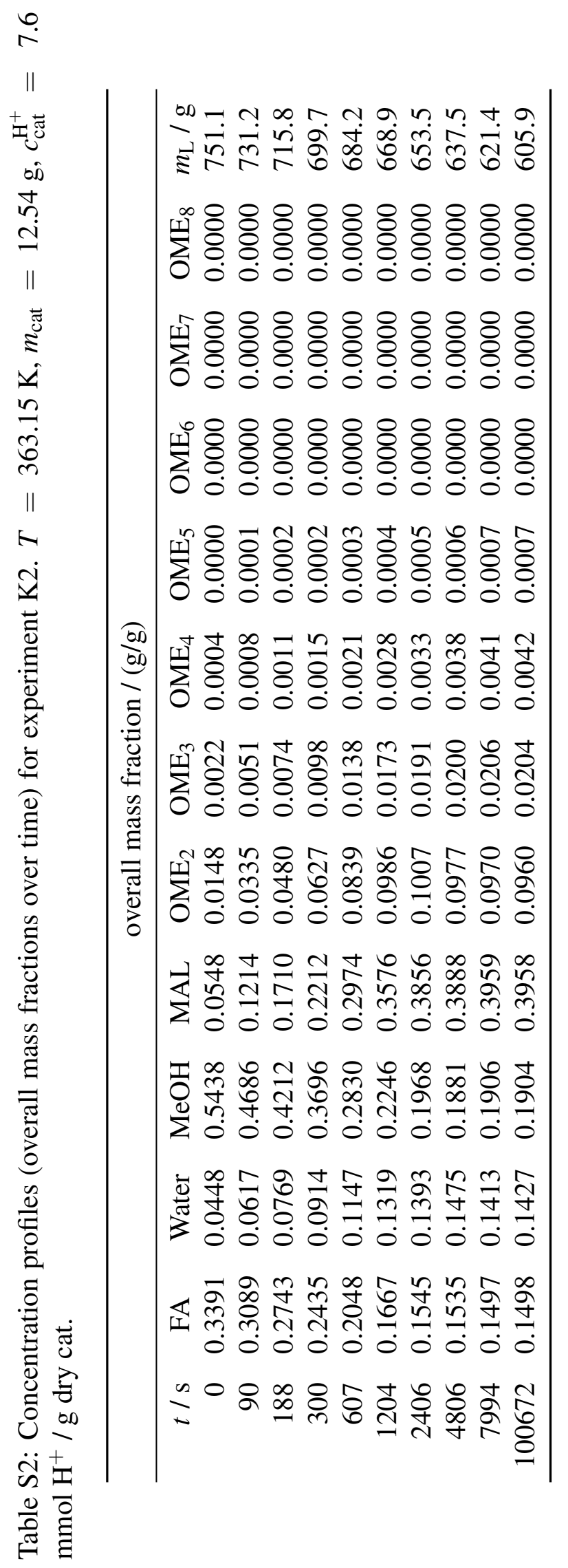




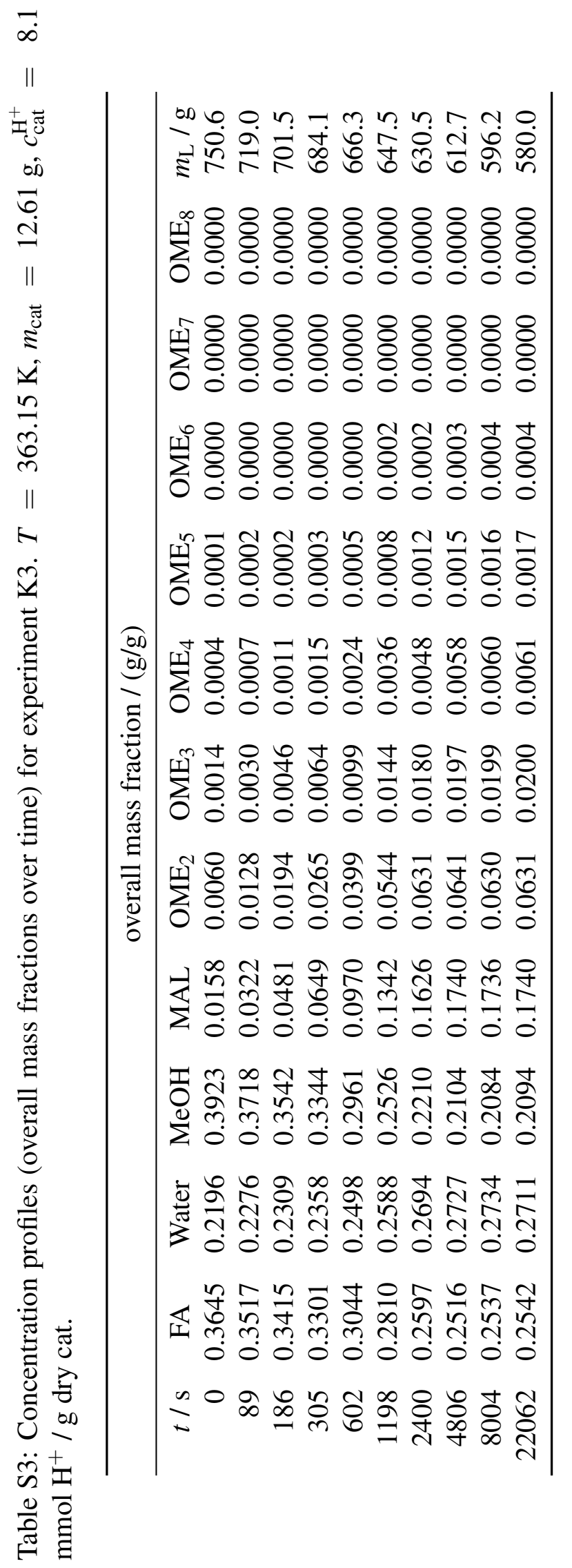




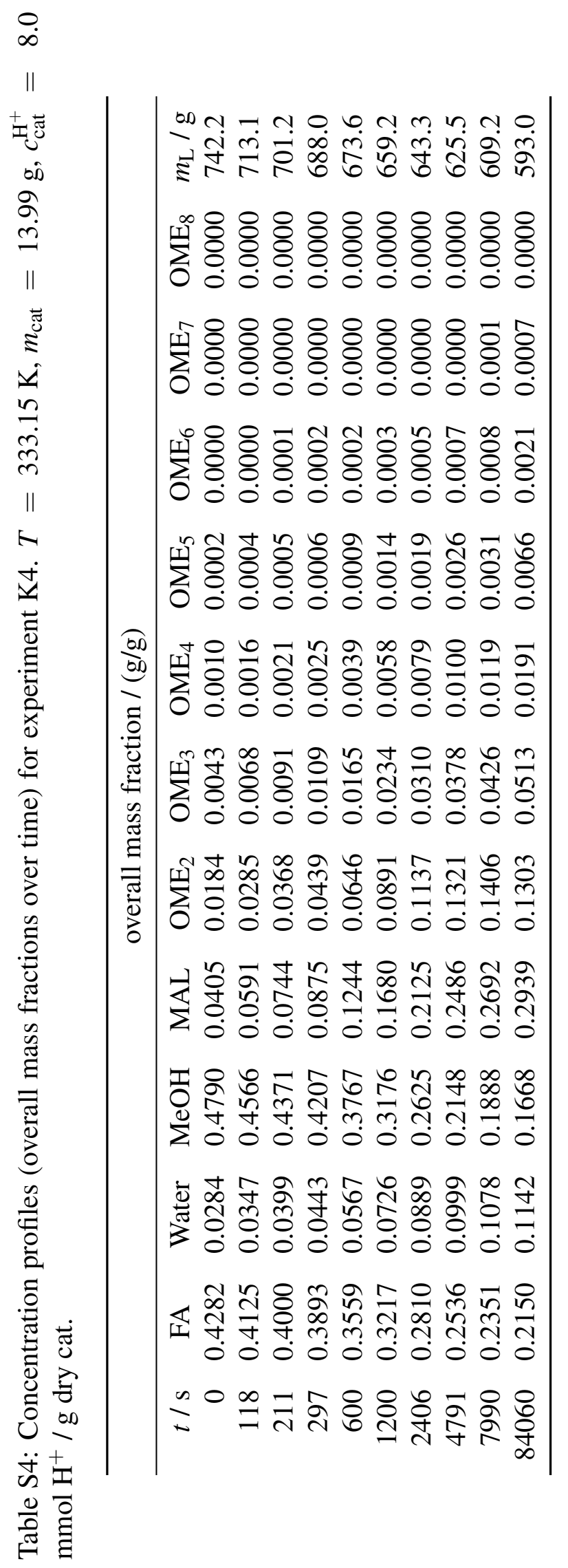




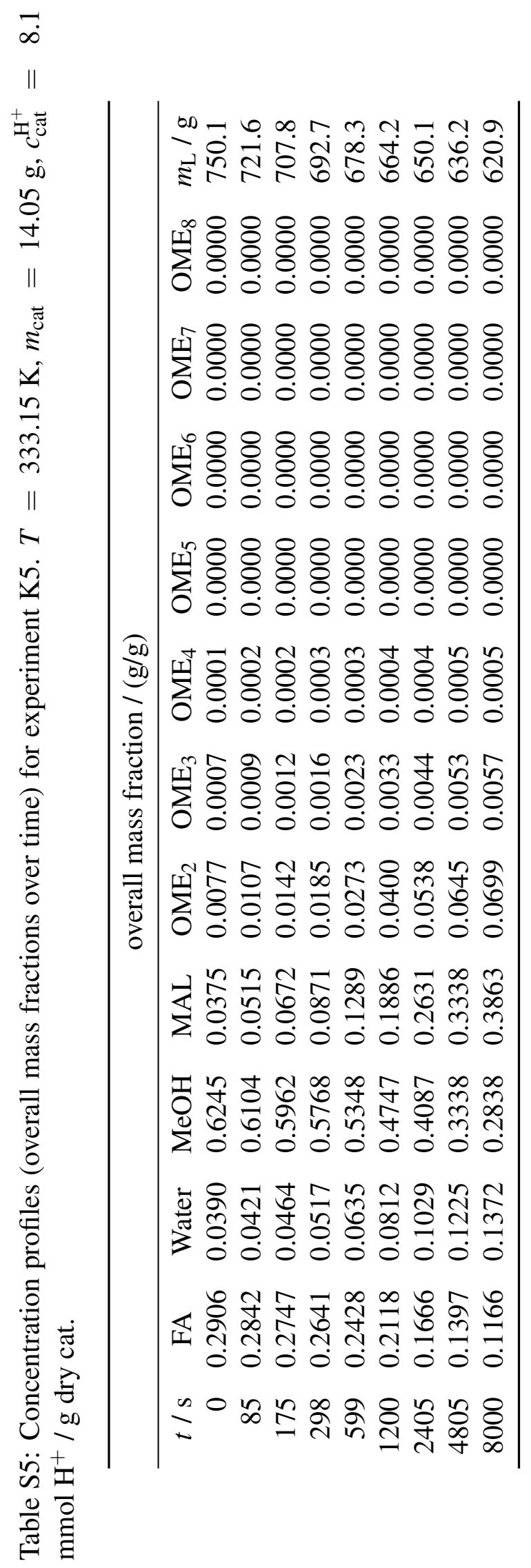




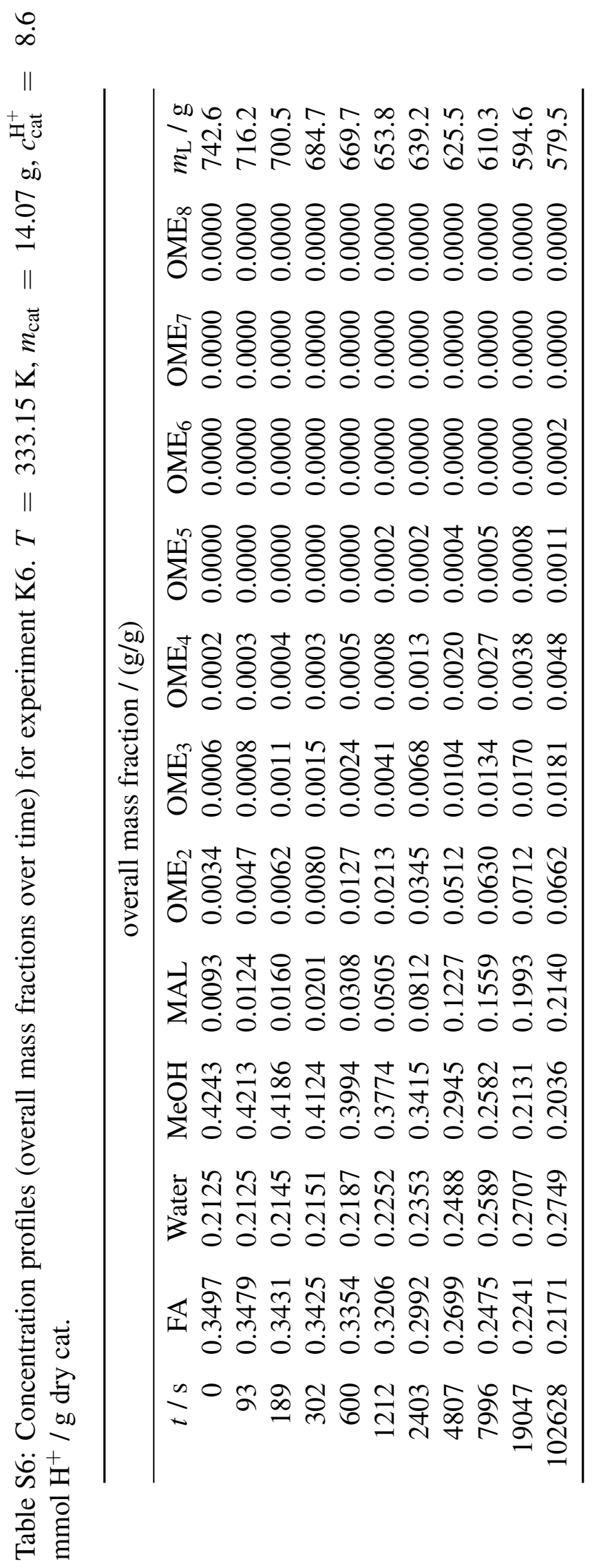




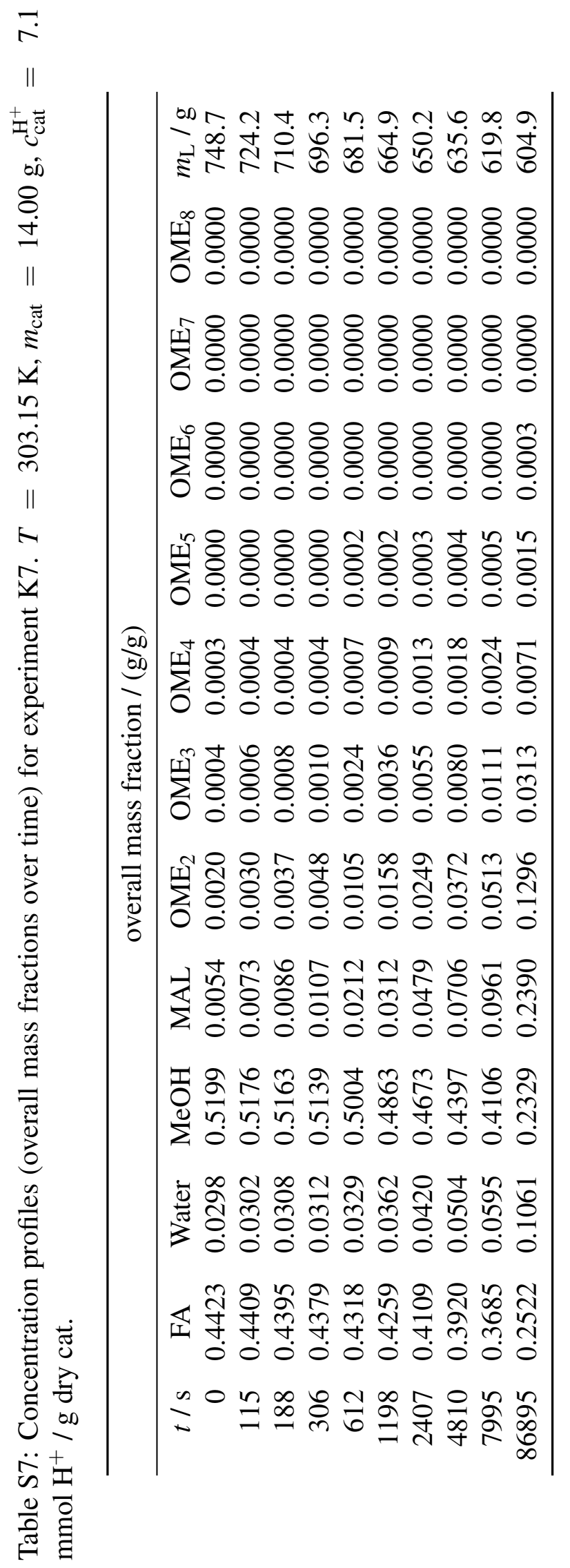




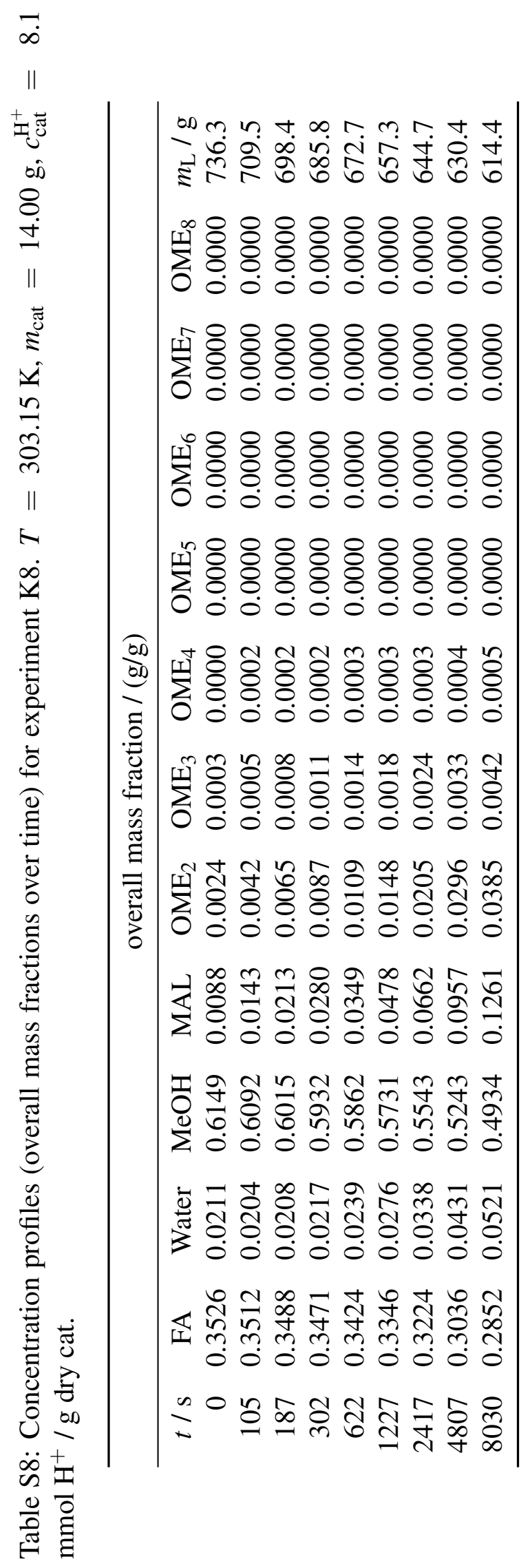




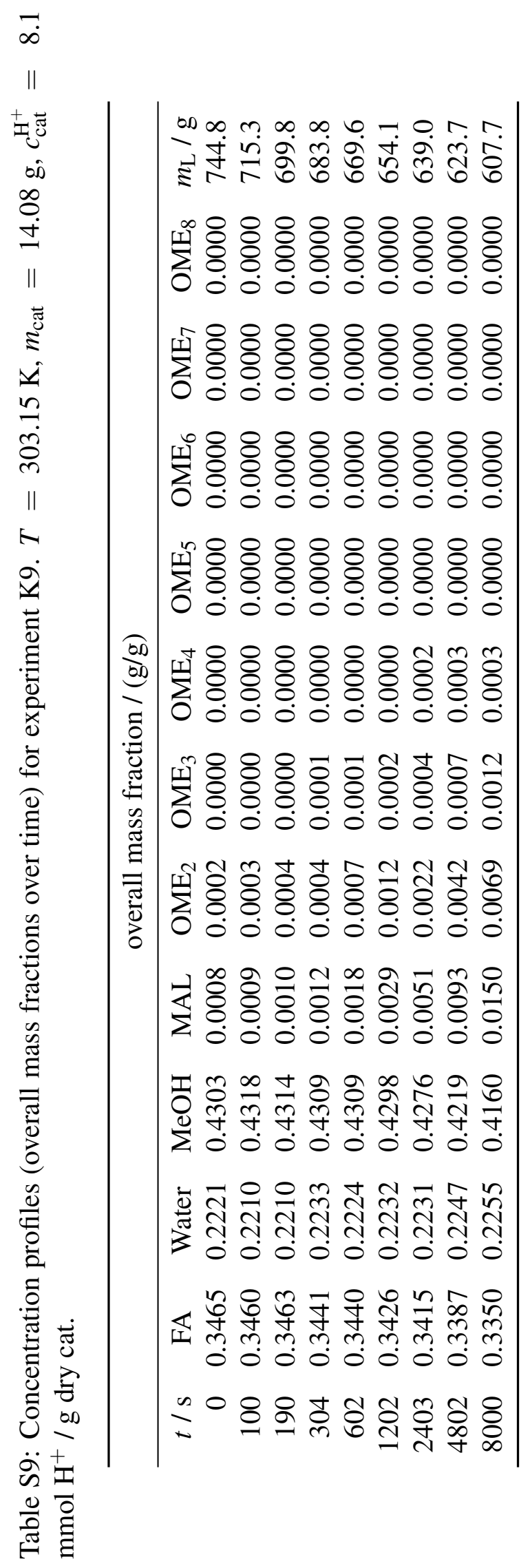




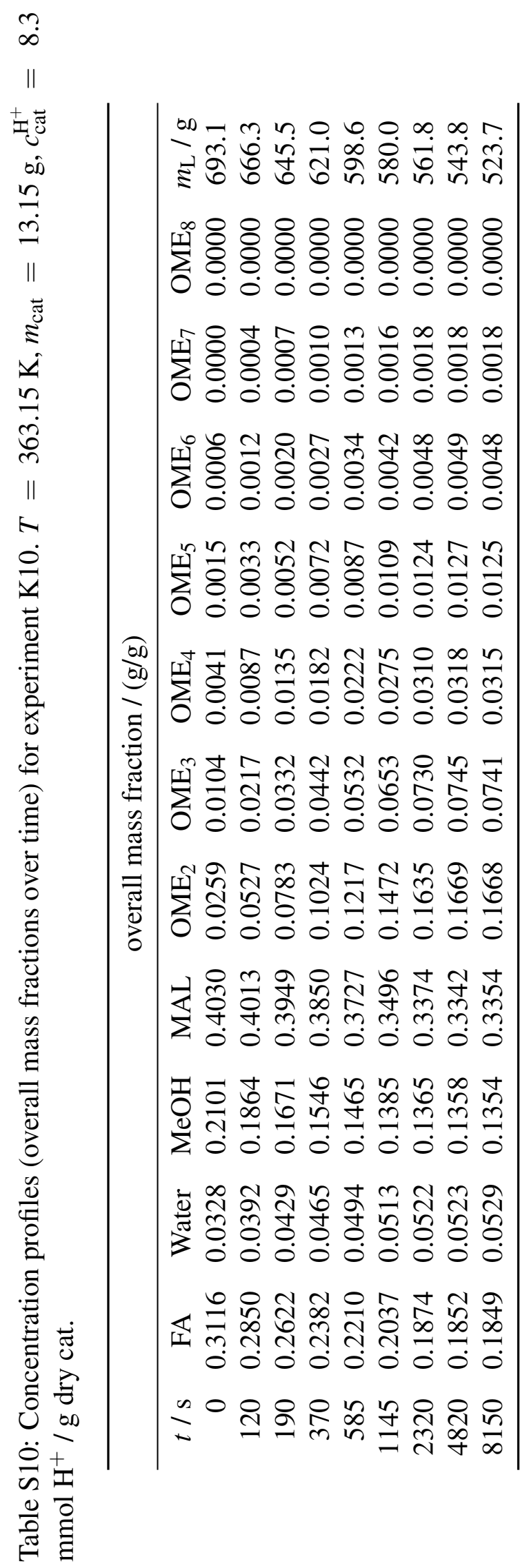




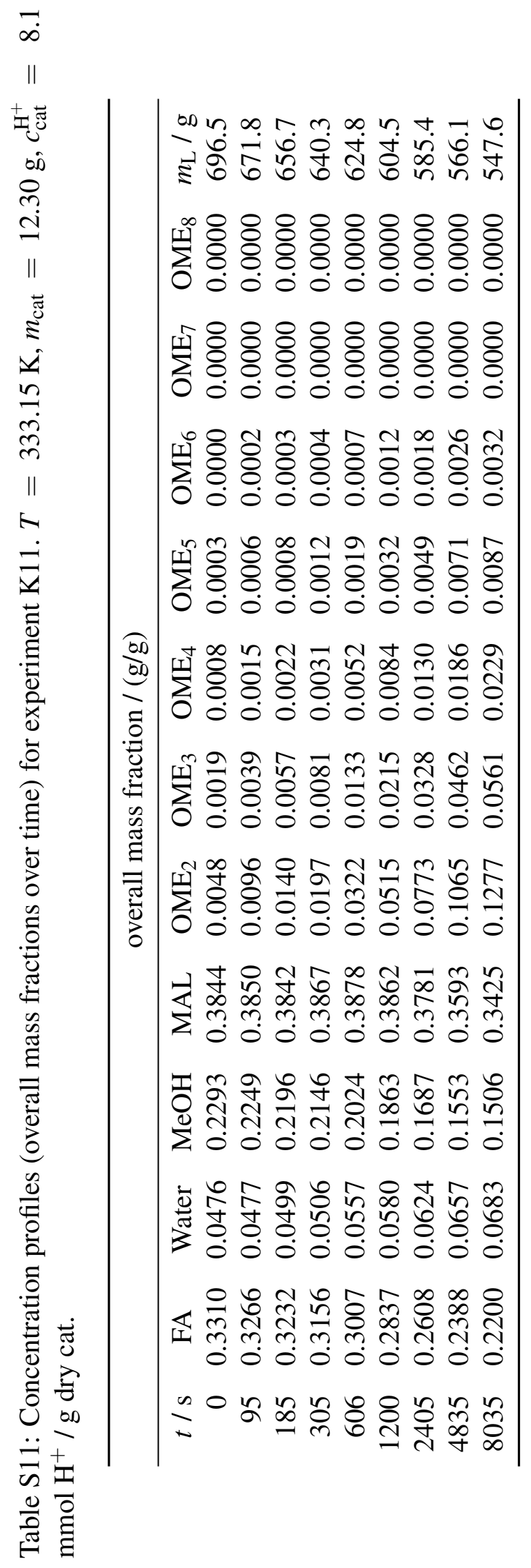




\section{Correlations for the Chemical Equilibrium Constants}

The temperature dependency of all chemical equilibrium constants $K_{j}(T)$ is given by Eq. (1), the integrated van't Hoff equation with parameters $A_{j}$ and $B_{j}$.

$$
\ln K_{j}(T)=A_{j}+\frac{B_{j}}{T / \mathrm{K}}
$$

The chemical equilibrium constants for the acetalization reactions $K_{6, n}$ are calculated from the chemical equilibrium constants published previously $\left(K_{4, n}, K_{5}, K_{7}, K_{8, n}\right)^{1}$ according to Eqs. (2) and (3). This ensures full consistency of the equilibrium model with the kinetic model,

$$
\begin{aligned}
& K_{6,2}=\frac{K_{5} \cdot K_{7}}{K_{4,2}} \\
& K_{6, n}=\frac{K_{5} \cdot K_{7} \cdot \prod_{\chi=3}^{n} K_{8, \chi}}{\prod_{\chi=2}^{n} K_{4, \chi}} ; n \geq 3
\end{aligned}
$$

Although the chemical equilibrium constants for the growth mechanism $K_{7}$ and $K_{8, n}$ were found to be independent of chain length $n,{ }^{1}$ the chemical equilibrium constants for the acetalization mechanism $K_{6, n}$ depend on chain length according to Eqs. (2) and (3). Parameters $A_{j}$ and $B_{j}$ for the calculation of the chemical equilibrium constants for all reactions in the present work are given in Table S12. 
Table S12: Parameters for the calculation of the chemical equilibrium constants (based on mole fractions) for all reactions in the present work using the correlation: $\ln K_{j}(T)=A_{j}+B_{j} /(T / \mathrm{K}){ }^{1,2}$ The numbering of every reaction in this table is identical to the numbering of the reactions in the main paper of this publication.

\begin{tabular}{lcc}
\hline & $A_{j}$ & $B_{j}$ \\
\hline$K_{1}$ & -2.3250 & 2579.0 \\
$K_{2,2}$ & -2.3105 & 3139.9 \\
$K_{2, n}(n \geq 3)$ & -2.4334 & 3039.4 \\
$K_{3}$ & -1.9020 & 3512.0 \\
$K_{4, n}(n \geq 2)$ & -2.2496 & 3008.8 \\
$K_{5}$ & 0.8147 & 340.25 \\
$K_{6,2}$ & 0.6489 & 361.09 \\
$K_{6,3}$ & 0.4831 & 381.92 \\
$K_{6,4}$ & 0.3173 & 402.75 \\
$K_{6,5}$ & 0.1515 & 423.59 \\
$K_{6,6}$ & -0.0143 & 444.42 \\
$K_{6,7}$ & -0.1801 & 465.25 \\
$K_{6,8}$ & -0.3459 & 486.09 \\
$K_{7}$ & -2.4154 & 3029.6 \\
$K_{8, n}(n \geq 3)$ & -2.4154 & 3029.6 \\
\hline
\end{tabular}




\section{True Composition and Overall Composition}

This section provides a mathematical description of the relations between the true- and the overall composition, respectively. The overall amounts of substance $\widetilde{n}_{i}$ are calculated from the true amounts of substance $n_{i}$ from Eqs. (4) to (8).

$$
\begin{gathered}
\widetilde{n}_{\mathrm{FA}}=n_{\mathrm{FA}}+\sum_{i=1}^{\infty} i \cdot n_{\mathrm{MG}_{i}}+\sum_{i=1}^{\infty} i \cdot n_{\mathrm{HF}_{i}} \\
\widetilde{n}_{\mathrm{H}_{2} \mathrm{O}}=n_{\mathrm{H}_{2} \mathrm{O}}+\sum_{i=1}^{\infty} n_{\mathrm{MG}_{i}} \\
\widetilde{n}_{\mathrm{MeOH}}=n_{\mathrm{MeOH}}+\sum_{i=1}^{\infty} n_{\mathrm{HF}_{i}} \\
\widetilde{n}_{\mathrm{MAL}}=n_{\mathrm{MAL}} \\
\widetilde{n}_{\mathrm{OME}_{n}}=n_{\mathrm{OME}_{n}}
\end{gathered}
$$

The total overall amount of substance $n_{\text {tot }}$ is given by Eq. (9) and the overall mole fractions $\tilde{x}_{i}$ are calculated from Eq. (10).

$$
\begin{gathered}
\widetilde{n}_{\mathrm{tot}}=\widetilde{n}_{\mathrm{FA}}+\widetilde{n}_{\mathrm{H}_{2} \mathrm{O}}+\widetilde{n}_{\mathrm{MeOH}}+\widetilde{n}_{\mathrm{MAL}}+\sum_{n=2}^{\infty} \widetilde{n}_{\mathrm{OME}_{n}} \\
\widetilde{x}_{i}=\frac{\widetilde{n}_{i}}{\widetilde{n}_{\mathrm{tot}}}
\end{gathered}
$$

\section{Concentration Profile Diagrams}

The experimentally obtained concentration profiles for experiments K4 to K9 are shown together with the model results in Figure S1 to Figure S6. For experiment K11, for which the educt mixture also comprises a significant amount of methylal, the model results are shown excluding the growth reactions in Figure S7 and including the growth reactions in Figure S8. 

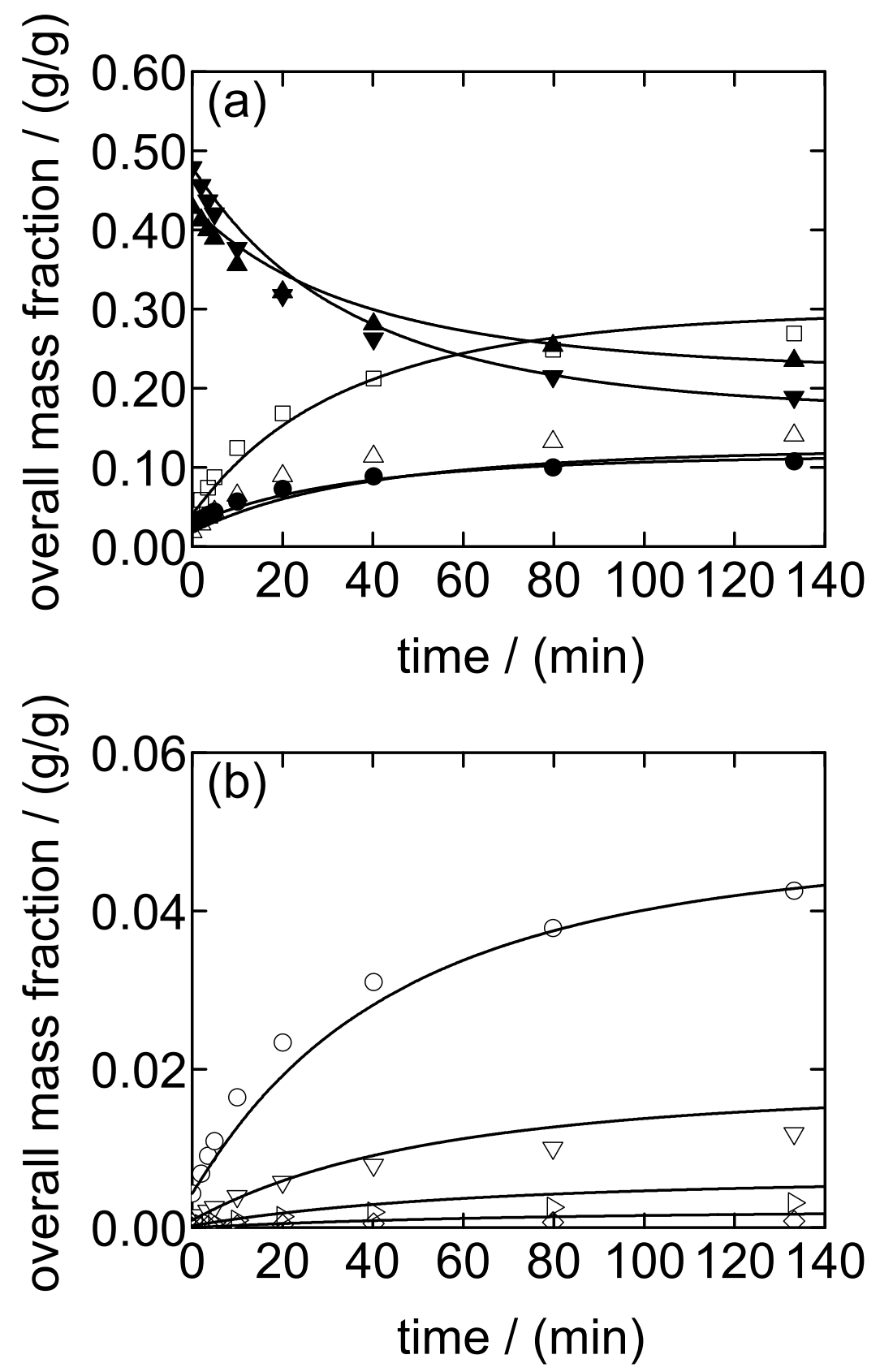

Figure S1: Overall concentration profiles of kinetic experiment $\mathrm{K} 4(T=333.15 \mathrm{~K})$. (a) Formaldehyde ( $\mathbf{\Delta})$, water $(\bullet)$, methanol $(\mathbf{\nabla})$, methylal $(\square), \mathrm{OME}_{2}(\triangle)$; (b) $\mathrm{OME}_{3}(\circ), \mathrm{OME}_{4}(\nabla), \mathrm{OME}_{5}$ $(\triangleright), \mathrm{OME}_{6}(\diamond)$. Pseudo-homogeneous model: solid lines (-). 

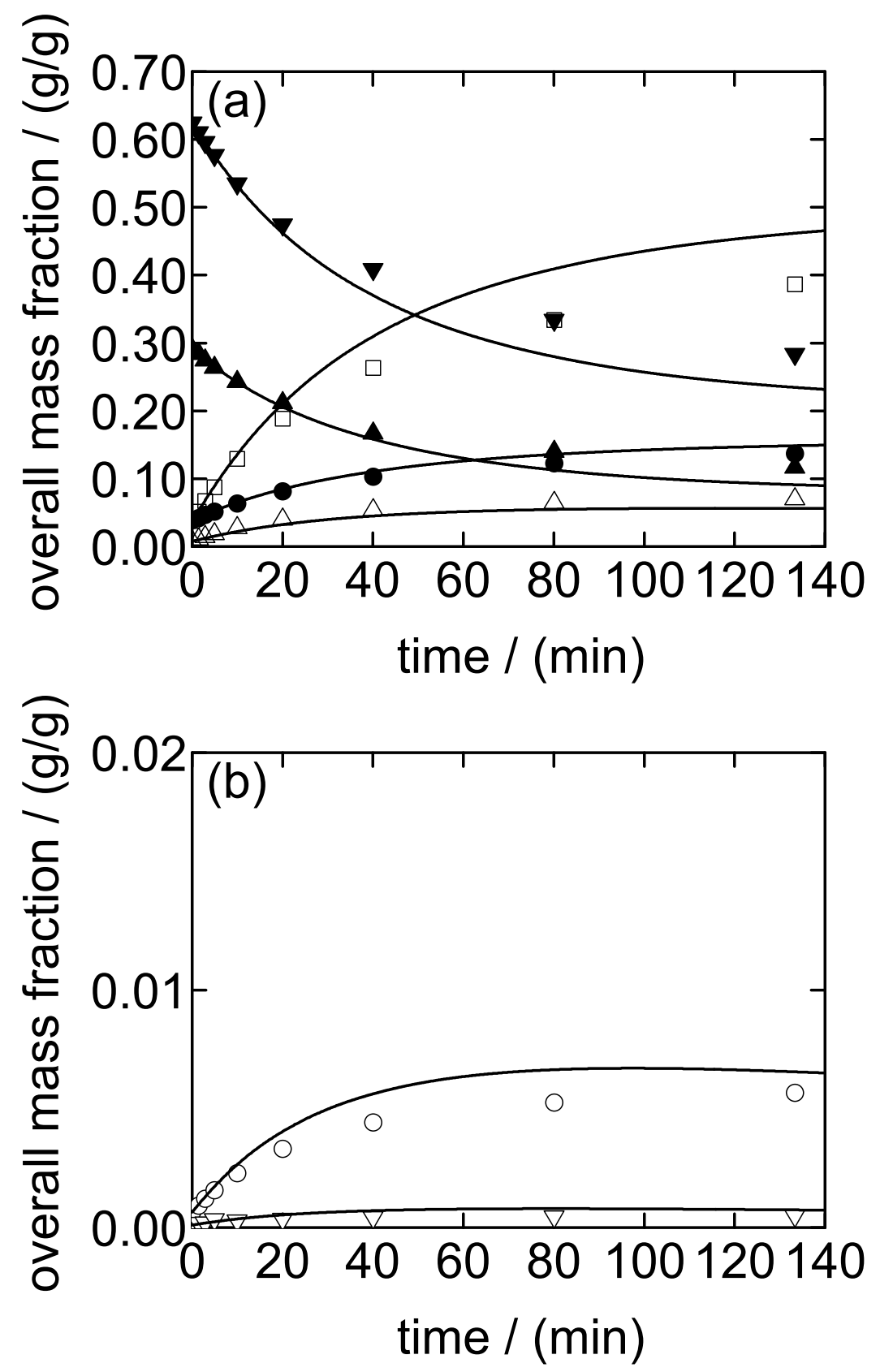

Figure S2: Overall concentration profiles of kinetic experiment K5 $(T=333.15 \mathrm{~K})$. (a) Formaldehyde (ム), water $(\bullet)$, methanol $(\boldsymbol{\nabla})$, methylal $(\square), \mathrm{OME}_{2}(\triangle)$; (b) $\mathrm{OME}_{3}(\circ), \mathrm{OME}_{4}(\nabla)$. Pseudohomogeneous model: solid lines (-). 

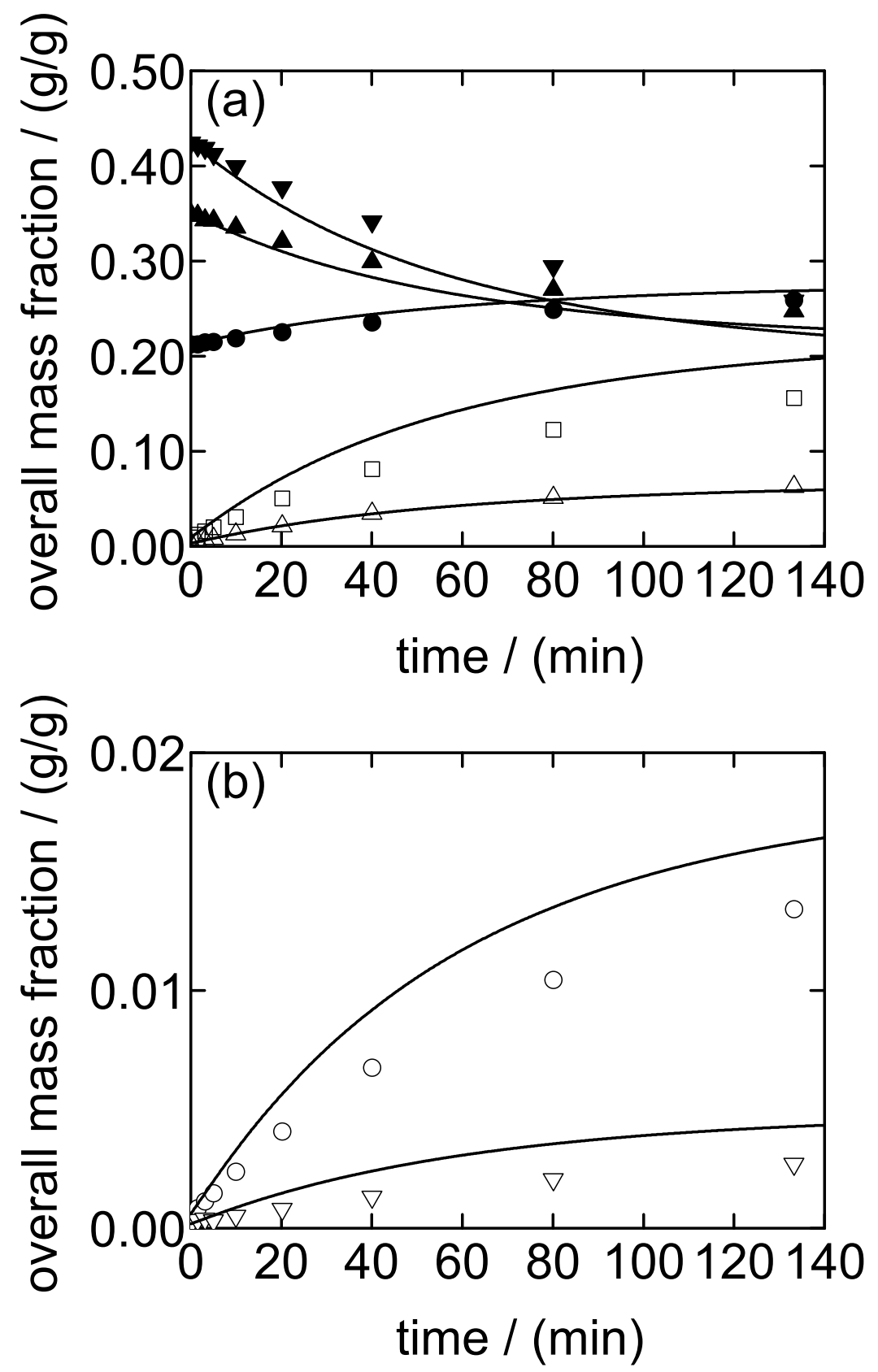

Figure S3: Overall concentration profiles of kinetic experiment K6 $(T=333.15 \mathrm{~K})$. (a) Formaldehyde ( $\mathbf{\Delta})$, water $(\bullet)$, methanol $(\boldsymbol{\nabla})$, methylal $(\square), \mathrm{OME}_{2}(\triangle)$; (b) $\mathrm{OME}_{3}(\circ), \mathrm{OME}_{4}(\nabla)$. Pseudohomogeneous model: solid lines (-). 

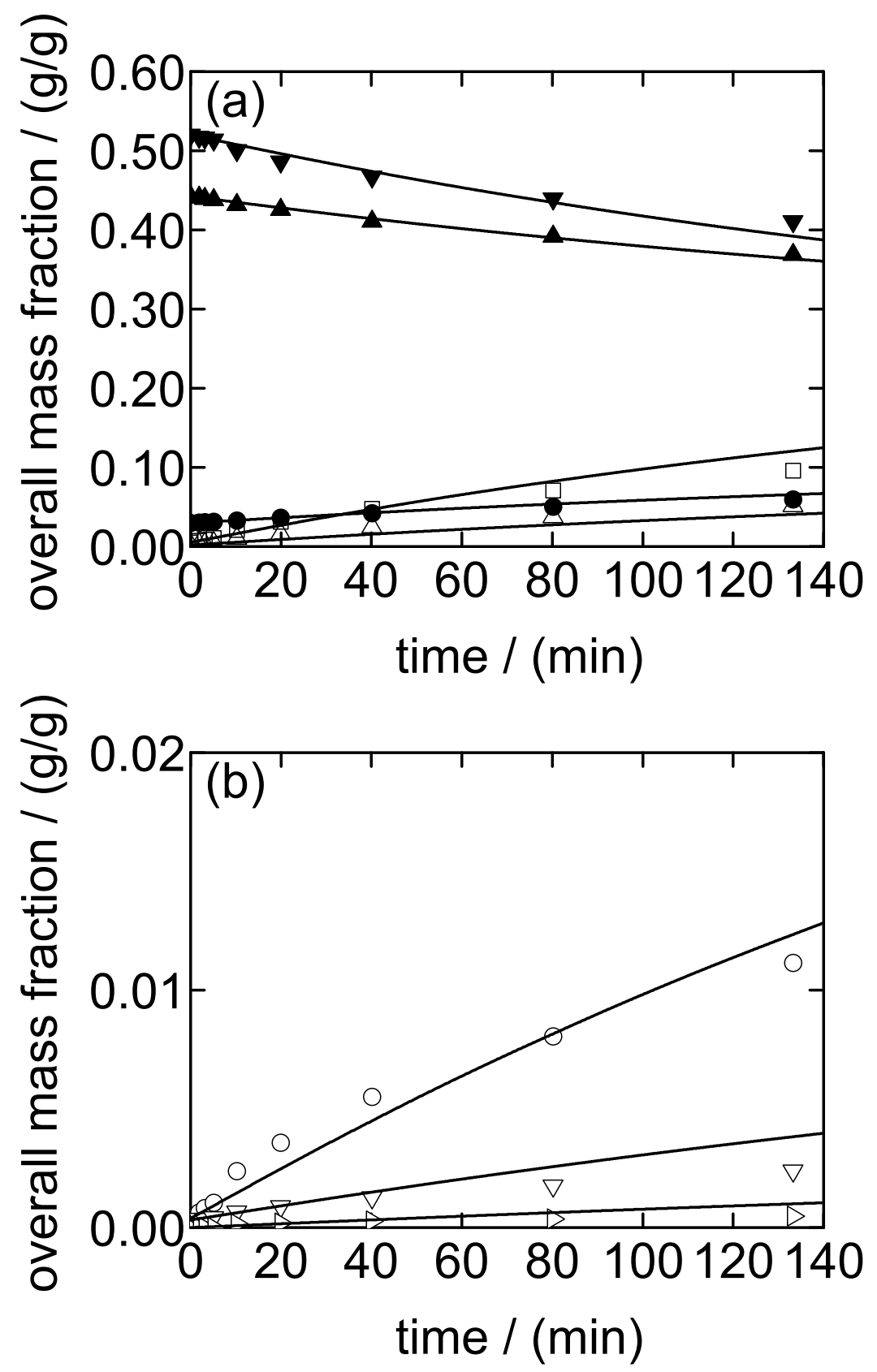

Figure S4: Overall concentration profiles of kinetic experiment $\mathrm{K} 7(T=303.15 \mathrm{~K})$. (a) Formaldehyde (₫), water $(\bullet)$, methanol $(\mathbf{v})$, methylal $(\square), \mathrm{OME}_{2}(\triangle)$; (b) $\mathrm{OME}_{3}(\circ), \mathrm{OME}_{4}(\nabla), \mathrm{OME}_{5}$ $(\triangleright)$. Pseudo-homogeneous model: solid lines (-). 

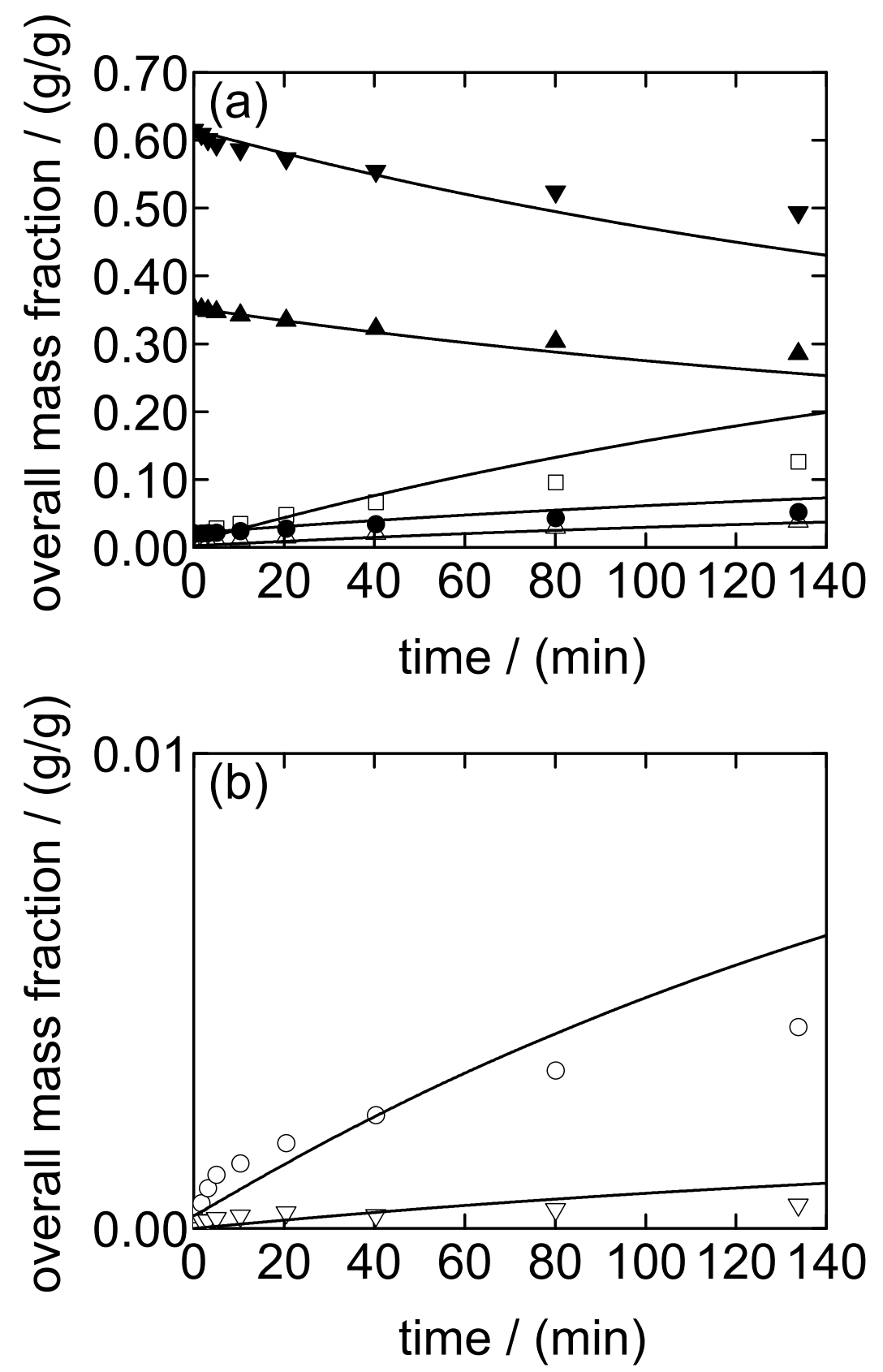

Figure S5: Overall concentration profiles of kinetic experiment $\mathrm{K} 8(T=303.15 \mathrm{~K})$. (a) Formaldehyde ( $\mathbf{\Delta})$, water $(\bullet)$, methanol $(\boldsymbol{\nabla})$, methylal $(\square), \mathrm{OME}_{2}(\triangle)$; (b) $\mathrm{OME}_{3}(\circ), \mathrm{OME}_{4}(\nabla)$. Pseudohomogeneous model: solid lines (-). 


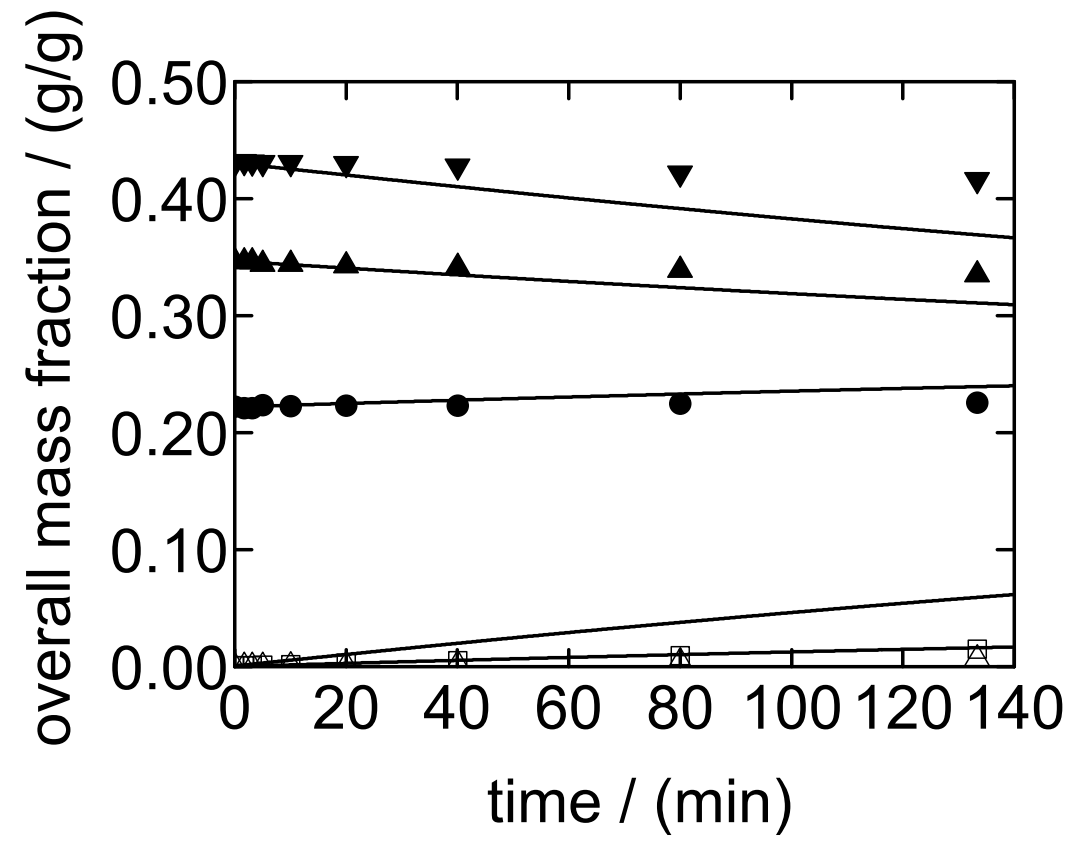

Figure S6: Overall concentration profiles of kinetic experiment $\mathrm{K} 9(T=303.15 \mathrm{~K})$. Formaldehyde (ム), water $(\bullet)$, methanol $(\boldsymbol{\nabla})$, methylal $(\square), \mathrm{OME}_{2}(\triangle)$. Pseudo-homogeneous model: solid lines (-). 

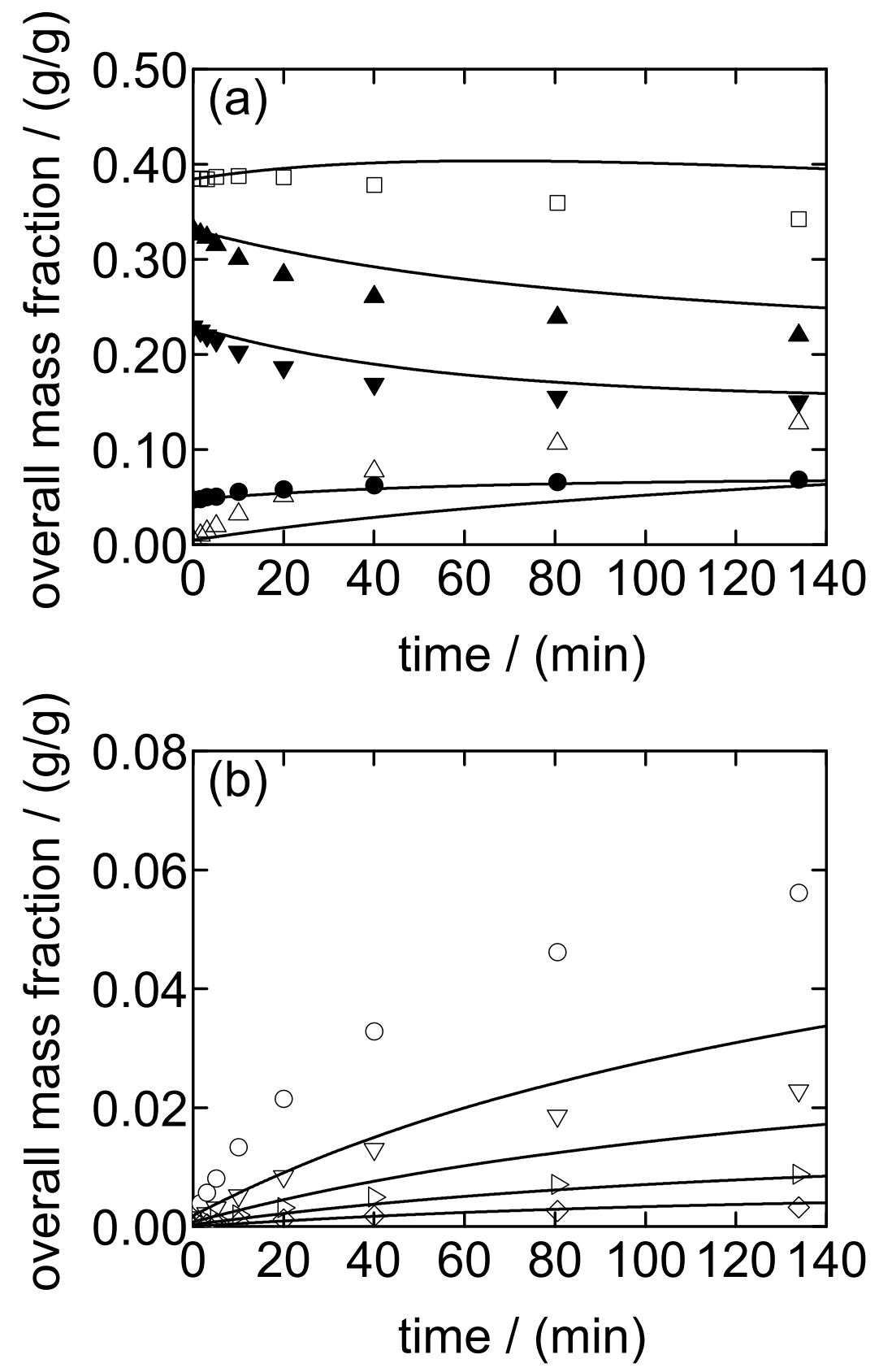

Figure S7: Overall concentration profiles of kinetic experiment $\mathrm{K} 11$ ( $T=333.15 \mathrm{~K})$. (a) Formaldehyde $(\boldsymbol{\Delta})$, water $(\bullet)$, methanol $(\boldsymbol{\nabla})$, methylal $(\square), \mathrm{OME}_{2}(\triangle)$; (b) $\mathrm{OME}_{3}(\circ), \mathrm{OME}_{4}(\nabla)$, $\mathrm{OME}_{5}(\triangleright), \mathrm{OME}_{6}(\diamond)$. Pseudo-homogeneous model without growth reactions $(k \mathrm{G}=0)$ : solid lines (-). If a significant amount of methylal is present in the educt mixture, the acetalization mechanism alone is not able to describe the experimental results. 

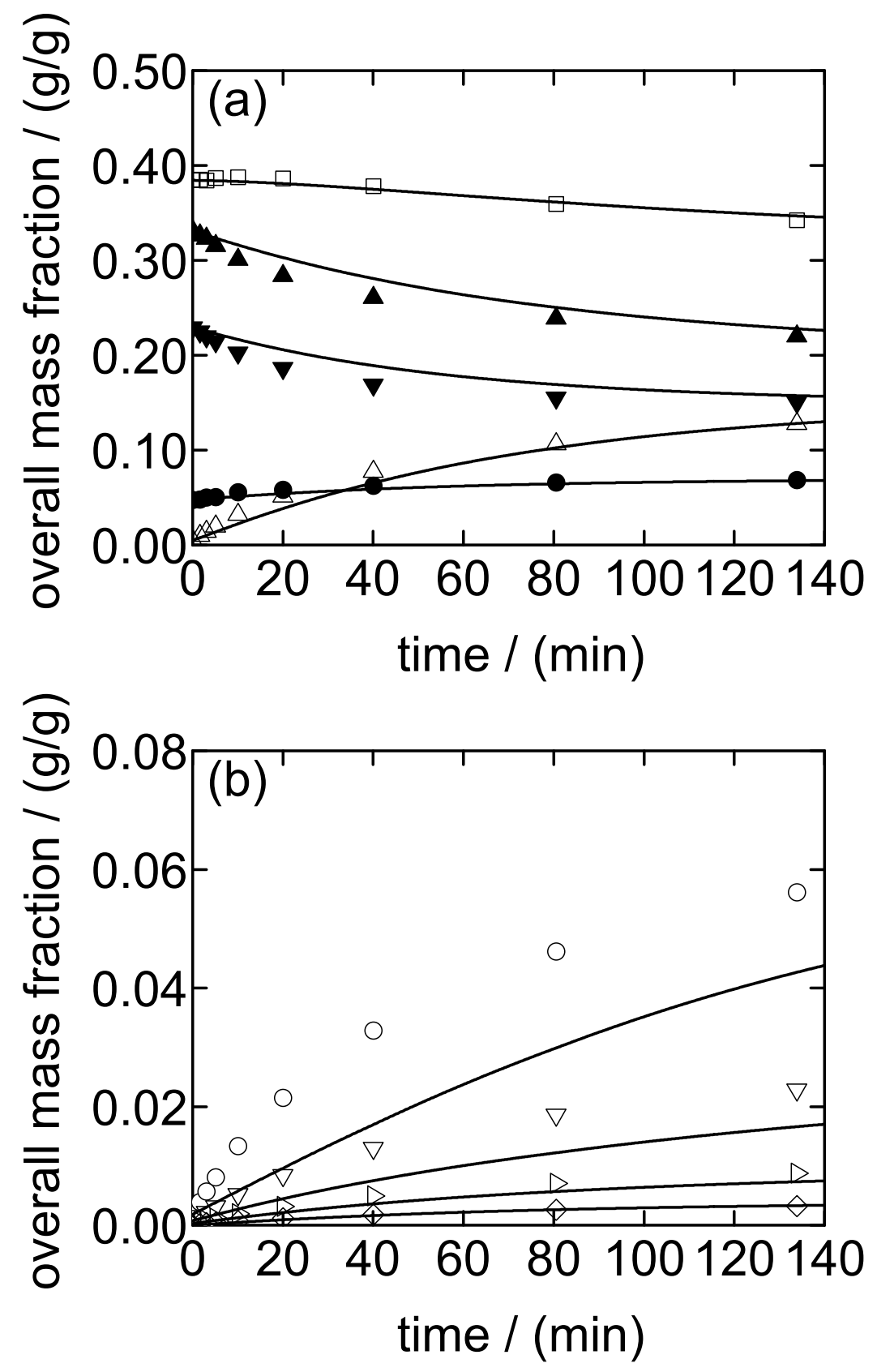

Figure S8: Overall concentration profiles of kinetic experiment $\mathrm{K} 11$ ( $T=333.15 \mathrm{~K})$. (a) Formaldehyde $(\boldsymbol{\Delta})$, water $(\bullet)$, methanol $(\boldsymbol{\nabla})$, methylal $(\square), \mathrm{OME}_{2}(\triangle)$; (b) $\mathrm{OME}_{3}(\circ), \mathrm{OME}_{4}$ $(\nabla), \mathrm{OME}_{5}(\triangleright), \mathrm{OME}_{6}(\diamond)$. Pseudo-homogeneous model with acetalization- and growth reactions: solid lines (-). In contrast to Figure S7, the growth reactions are considered here. This leads to a good description of the kinetic behavior. 


\section{Appendix}

\section{Additional Nomenclature}

Symbols and indices:

$A_{j}, B_{j} \quad$ Temperature correlation parameters

$m_{\mathrm{L}} \quad$ Mass of the liquid reacting mixture

\section{References}

1. Schmitz, N.; Homberg, F.; Berje, J.; Burger, J.; Hasse, H. Chemical equilibrium of the synthesis of poly(oxymethylene) dimethyl ethers from formaldehyde and methanol in aqueous solutions. Ind. Eng. Chem .Res. 2015, 54, 6409-6417.

2. Hahnenstein, I.; Albert, M.; Hasse, H.; Kreiter, C. G.; Maurer, G. NMR spectroscopic and densimetric study of reaction kinetics of formaldehyde polymer formation in water, deuterium oxide, and methanol. Ind. Eng. Chem. Res. 1995, 34, 440-450. 